Pacific Journal of Mathematics

STRICT LOCAL INCLUSION RESULTS BETWEEN SPACES OF 


\title{
STRICT LOCAL INCLUSION RESULTS BETWEEN SPACES OF FOURIER TRANSFORMS
}

\author{
WALTER R. BLOOM
}

Let $G$ denote a noncompact Hausdorff locally compact abelian group, $\Gamma$ its character group, and write $\left(L^{s}, l^{t}\right)^{\wedge}$ for the space of Fourier transforms of functions in the amalgam $\left(L^{s}, l^{t}\right)$. We show that for $1 \leqq p<q \leqq \infty$ the local inclusion $\left(L^{1}, l^{p}\right)^{\wedge} \stackrel{\text { loc }}{\subset}\left(L^{\infty}, l^{q}\right)^{\wedge}$ is strict, that is, given any nonvoid open subset $\Omega$ of $\Gamma$ there exists $f \in\left(L^{\infty}, l^{q}\right)$ such that $\hat{f}-\hat{g}$ does not vanish on $\Omega$ for any $g \in\left(L^{1}, l^{p}\right)$. If in addition $G$ is assumed to be second countable then we show there exists such an $f$ independent of the choice of $\Omega$. Of special interest is the case, included in the above results, where the amalgams $\left(L^{1}, l^{q}\right),\left(L^{\infty}, l^{p}\right)$ are replaced by $L^{p}(G), L^{q}(G)$ respectively.

Throughout $G$ will denote a noncompact Hausdorff locally compact abelian group, with Haar measure $\lambda$ and character group $\Gamma$. $A(\Gamma)$ will denote the space of Fourier transforms of functions integrable over $G$, and $A_{c}(\Gamma)$ the subspace formed of functions whose supports are compact. For each compact set $\Xi \subset \Gamma$, write $A_{\varepsilon}(\Gamma)=$ $\{h \in A(\Gamma): \operatorname{supp}(h) \subset \Xi\}$. We give each space $A_{\varepsilon}(\Gamma)$ its normed topology as $\|\hat{f}\|=\|f\|_{1}, \hat{f} \in A_{\varepsilon}(\Gamma)$, and topologise $A_{c}(\Gamma)$ as the internal inductive limit of the spaces $A_{\varepsilon}(\Gamma)$.

For each $s, t \in[1, \infty]$ the amalgam $\left(L^{s}, l^{t}\right)$ is defined in the following way. Using the structure theorem ([6], (24.30)) we write $G=$ $R^{a} \times G_{0}$, where $a$ is a nonnegative integer and $G_{0}$ contains a compact open subgroup $H$. We put $J=Z^{a} \times G_{0} / H, L=[0,1)^{a} \times H$ and write $G$ as the disjoint union $\bigcup_{\alpha} L_{\alpha}$ where, for each $\alpha=\left(n_{1}, \cdots, n_{a}, y+H\right) \in$ $J, L_{\alpha}=\left(n_{1}, \cdots, n_{a}, y\right)+L$. Given $f \in L_{\mathrm{loc}}^{\mathrm{s}}(G)$ write

$$
\|f\|_{s, t}=\left(\sum_{\alpha}\left(\int_{L_{\alpha}}|f|^{s} d \lambda\right)^{t / s}\right)^{1 / t},
$$

with the usual modification if $\max \{s, t\}=\infty$, and

$$
\left(L^{s}, l^{t}\right)=\left\{f \in L_{\mathrm{loc}}^{s}(G):\|f\|_{s, t}<\infty\right\} .
$$

Each amalgam $\left(L^{s}, l^{t}\right)$ is a Banach space and, provided $s, t<\infty$, its dual space is isometrically isomorphic to $\left(L^{s^{\prime}}, l^{t^{\prime}}\right.$ ) (where $s^{\prime}, t^{\prime}$ denote the indices conjugate to $s, t$ respectively); for this and other results on amalgams see [9], §3.

Here we give three results for amalgams, which will be referred to in the sequel. 
THEOREM A. The translation operators $\tau_{b}$ defined by $\tau_{b} f: x \rightarrow$ $f(x-b)$ are uniformly bounded on $\left(L^{s}, l^{t}\right)$ for all $s, t \in[1, \infty]$.

THEOREM B. For any compact set $\Xi \subset \Gamma$ there exists $k \in\left(L^{\infty}, l^{1}\right)$ with $\hat{k}=1$ on $\Xi$.

THeORem C. Let $f \in\left(L^{p_{1}}, l^{p_{2}}\right), g \in\left(L^{q_{1}}, l^{q_{2}}\right)$ and suppose that $1 / r_{i}=$ $1 / p_{i}+1 / q_{i}-1 \geqq 0$ for $i=1,2$. Then $f * g \in\left(L^{r_{1}}, l^{r_{2}}\right)$ and $\|f * g\|_{r_{1}, r_{2}} \leqq$ $K\|f\|_{p_{1}, p_{2}}\|g\|_{q_{1}, q_{2}}$, where $K$ is a constant.

The proof of Theorem 3.3 in [9] applies equally well to give Theorem A, and Theorem B is just [9], Theorem 3.1. Theorem C follows from Theorem $A$ and the results of [1], $\S 7(i)$.

For each $f \in\left(L^{1}, l^{\infty}\right)$ we define the Fourier transform $\hat{f}$ as the continuous linear functional on $A_{c}(\Gamma)$ given by

$$
\hat{f}(h)=f\left(\hat{h}_{\vee}\right), h \in A_{c}(\Gamma),
$$

where $\hat{h}_{\vee}$ is the reflection of the inverse Fourier transform of $h$ and $f(g)=\int_{G} f g d \lambda$ (for a similar definition of the Fourier transform see Bertrandias and Dupuis ([2], $\S 4(a))$ ). That $\hat{f}$ is linear is clear, and continuity can be shown as follows. Since $A_{c}(\Gamma)$ is the inductive limit of the spaces $A_{\varepsilon}(\Gamma)$ we need only prove that $\hat{f}$ is continuous on each $A_{\varepsilon}(\Gamma)$. First note that if $h \in A_{\varepsilon}(\Gamma)$ then $\hat{h}_{\vee}=k * \hat{h}_{\vee} \epsilon$ $\left(L^{\infty}, l^{1}\right)$ by Theorem $\mathrm{C}$, where $k \in\left(L^{\infty}, l^{1}\right)$ is chosen as in Theorem B with $\hat{k}=1$ on $-\Xi$. Hence

$$
\begin{aligned}
|\hat{f}(h)|=\left|f\left(\hat{h}_{\vee}\right)\right|=\left|\int_{G} f \hat{h}_{\vee} d \lambda\right| & \leqq \sum_{\alpha} \int_{L_{\alpha}}\left|f \hat{h}_{\vee}\right| d \lambda \\
& \leqq \sum_{\alpha}\left(\int_{L_{\alpha}}|f| d \lambda \max _{L_{\alpha}}\left|\hat{h}_{\vee}\right|\right) \\
& \leqq\left(\max _{\alpha} \int_{L_{\alpha}}|f| d \lambda\right) \sum_{\alpha} \max _{L_{\alpha}}\left|\hat{h}_{\vee}\right| \\
& =\|f\|_{1, \infty}\left\|\hat{h}_{\vee}\right\|_{\infty, 1} \\
& \leqq K\|f\|_{1, \infty}\|k\|_{\infty, 1}\left\|\hat{h}_{\vee}\right\|_{1} \\
& =K\|f\|_{1, \infty}\|k\|_{\infty, 1}\|h\|,
\end{aligned}
$$

so that $\hat{f}$ is bounded, hence continuous, on $A_{\tilde{z}}(\Gamma)$.

It follows from [3], Theorem 3.1 (and the remarks at the beginning of [3], §3) that this definition of the Fourier transform agrees with that given by Gaudry in [5], 1 (who defines the Fourier transform as a suitable quasimeasure) for functions in $L^{p}(G)$, and in particular with that usually taken when $1<p \leqq 2$. It will also be convenient to think of the Fourier transform of $f \in L^{1}(G)$ as a 
linear functional on $A_{c}(\Gamma)$. We write $\left(L^{s}, l^{t}\right)^{\wedge}=\left\{\hat{f}: f \in\left(L^{s}, l^{t}\right)\right\}$.

Let $\Omega$ be a nonvoid open subset of $\Gamma$. We say that $\hat{f}$ vanishes on $\Omega$ if $\hat{f}(h)=0$ for all $h \in A_{c}(\Gamma)$ with $\operatorname{supp}(h) \subset \Omega$. Suppose that $1 \leqq p \leqq q \leqq \infty, g \in\left(L^{1}, l^{p}\right)$, and take $\Omega$ to be any nonvoid relatively compact open subset of $\Gamma$. By Theorem B we have the existence of $k \in\left(L^{\infty}, l^{1}\right)$ with $\hat{k}=1$ on $\Omega$. Writing $f=k * g$ it is seen that $f \in\left(L^{\infty}, l^{q}\right)$ and $\hat{f}-\hat{g}$ vanishes on $\Omega$. Thus we have that $\left(L^{1}, l^{p}\right)^{\wedge} \subset$ $\left(L^{\infty}, l^{2}\right)^{\wedge}$, where the inclusion is to be interpreted as holding locally. This has already been observed for the Lebesgue spaces when $G$ is the real line; see [8], Chapter VI, § 4.12.

Our main result (Theorem 1), which we prove with the aid of an extension to amalgams of a multiplier theorem of Hörmander, implies that this local inclusion is strict whenever $p<q$. In the case $q \in(1,2]$, with the amalgams $\left(L^{1}, l^{p}\right),\left(L^{\infty}, l^{q}\right)$ replaced by $L^{p}(G)$, $L^{q}(G)$ respectively, this result has been given previously by Fournier ([4], Theorem 1) with $\Omega$ only required to be a set with positive Haar measure. Fournier's proof is based on the construction of certain positive definite functions on $\Gamma$.

THEOREM 1. Let $1<q \leqq \infty$ and suppose $\Omega$ is a nonvoid open subset of $\Gamma$. Then there exists $f \in\left(L^{\infty}, l^{q}\right)$ such that for any $p \in$ $[1, q)$ and $g \in\left(L^{1}, l^{p}\right), \hat{f}-\hat{g}$ does not vanish on $\Omega$.

Proof. We first show that if $h \in L^{1}(G)$ with $h \geqq 0, h \neq 0$, then there exists nonnegative $f \in\left(L^{\infty}, l^{q}\right)$ such that $h * f \notin\left(L^{1}, l^{p}\right)$ for any $p \in[1, q)$. This is easy to see if $q=\infty$, since in this case $f=1$ satisfies the stated conditions.

For $q<\infty$ fix $p \in[1, q)$ and assume that $h * f \in\left(L^{1}, l^{p}\right)$ for all $f \in\left(L^{\infty}, l^{q}\right)$. Consider the map $T$, defined on $\left(L^{\infty}, l^{q}\right)$ by $T f=h * f$. By assumption $T$ maps $\left(L^{\infty}, l^{q}\right)$ into $\left(L^{1}, l^{p}\right) . \quad T$ is obviously linear and commutes with translations. Furthermore the Closed Graph Theorem shows that $T$ is continuous. Now the proof of Hörmander's theorem ([7], Theorem 1.1), which holds for all noncompact locally compact abelian groups, can be modified to show that $T=0$. This is clearly impossible if $h$ is nonzero, so there exists $f \in\left(L^{\infty}, l^{q}\right)$ such that $h * f \notin\left(L^{1}, l^{p}\right)$. Since $h \geqq 0$ the same is true if $f$ is replaced by $|f|$. Now let $\left(p_{n}\right), p_{n} \geqq 1$, be any strictly increasing sequence of numbers converging to $q$. Choose a corresponding sequence $\left(f_{n}\right)$ of nonnegative functions in $\left(L^{\infty}, l^{q}\right)$ such that for each $n \in\{1,2, \cdots\}$, $h * f_{n} \notin\left(L^{1}, l^{p_{n}}\right)$. We assert that

$$
f=\sum_{n=1}^{\infty} n^{-2}\left\|f_{n}\right\|_{\infty, q}^{-1} f_{n}
$$


is a suitable choice of $f$; indeed, if there exists $p \in[1, q)$ such that $h * f \in\left(L^{1}, l^{p}\right)$ then, choosing $n_{0}$ such that $p_{n_{0}} \in[p, q)$, we would have (recall that for each $n, h * f_{n} \geqq 0$ )

$$
h * f_{n_{0}} \in\left(L^{1}, l^{p}\right) \subset\left(L^{1}, l^{p_{n_{0}}}\right),
$$

contradicting the choice of $f_{n_{0}}$.

Now choose $\gamma \in \Omega$ and nonzero $h \in A_{c}(\Gamma)$ such that supp $(h) \subset$ $-\gamma+\Omega$ and $\hat{h} \geqq 0$ (this is possible using [6], (31.34) and the fact that $-\gamma+\Omega$ is a neighbourhood of 0 ). From the first part of the proof there exists $f_{0} \in\left(L^{\infty}, l^{q}\right)$ such that $\hat{h} * f_{0} \notin\left(L^{1}, l^{p}\right)$ for any $p \in[1, q)$. Then $f=\gamma f_{0}$ satisfies the conditions of the theorem, for if there exists $p \in[1, q)$ and $g \in\left(L^{1}, l^{p}\right)$ such that $\hat{f}-\hat{g}$ vanishes on $\Omega$ then, since $(\bar{\gamma} f-\bar{\gamma} g)^{\wedge}$ vanishes on $-\gamma+\Omega$, we would have

$$
\hat{h} *(\bar{\gamma} f-\bar{\gamma} g)(x)=(\bar{\gamma} f-\bar{\gamma} g)^{\wedge}(x h)=0
$$

for all $x \in G$ (where $(x h)(\gamma)=\gamma(x) h(\gamma))$. But this gives $\hat{h} * f_{0}=\hat{h} * \bar{\gamma} g \epsilon$ $\left(L^{1}, l^{p}\right)$, a contradiction of our choice of $f_{0}$.

In the case where $G$ is second countable $f$ in Theorem 1 can be chosen independently of the nonvoid open set $\Omega$.

TheOREM 2. Let $G$ be a second countable noncompact locally compact abelian group. If $1 \leqq p<q \leqq \infty$ then there exists $f \in\left(L^{\infty}, l^{q}\right)$ such that, for any nonvoid open set $\Omega \subset \Gamma$, there is no $g \in\left(L^{1}, l^{p}\right)$ for which $\hat{f}-\hat{g}$ vanishes on $\Omega$.

Proof. Since $G$ is second countable so is $\Gamma$ (see [6], (24.14)). Suppose to the contrary that no such $f$ exists when $g$ is restricted to lie in $L^{p}(G)$. We consider $p>1$ and make use of Baire's category theorem to derive a contradiction.

For each pair of positive integers $m, n$ define $T_{m}\left(\Omega_{n}\right)=\left\{f \in\left(L^{\infty}\right.\right.$, $\left.l^{q}\right): \hat{f}-\hat{g}$ vanishes on $\Omega_{n}$ for some $\left.g \in L^{p}(G),\|g\|_{p} \leqq m\right\}$, where $\left\{\Omega_{n}: n=1,2, \cdots\right\}$ is a base for the topology of $\Gamma$ with each $\Omega_{n}$ nonvoid. Our assumption in the previous paragraph just says that $\bigcup_{m, n=1}^{\infty} T_{m}\left(\Omega_{n}\right)=\left(L^{\infty}, l^{q}\right)$. We shall show that for each $m, n \in\{1,2, \cdots\}$, $T_{m}\left(\Omega_{n}\right)$ is closed.

Let $\left(f_{s}\right)$ be a sequence of functions in $T_{m}\left(\Omega_{n}\right)$ converging in $\left(L^{\infty}, l^{q}\right)$ to $f$, say. Now for each $s \in\{1,2, \cdots\}$ there exists $g_{s} \in L^{p}(G)$ such that $\left\|g_{s}\right\|_{p} \leqq m$ and $\hat{f}_{s}-\hat{g}_{s}$ vanishes on $\Omega_{n}$. Using the theorem of Alaoglu we can deduce the existence of $g \in L^{p}(G)$ with $\|g\|_{p} \leqq m$, a weak*-cluster point of the sequence $\left(g_{s}\right)$. 
Now let $\varepsilon>0$ and $h \in A_{c}(\Gamma)$ with supp $(h) \subset \Omega_{n}$ be given. Choose $s$ such that $\left|g\left(\hat{h}_{\vee}\right)-g_{s}\left(\hat{h}_{\vee}\right)\right|<\varepsilon / 2$ and $\left|f\left(\hat{h}_{\vee}\right)-f_{s}\left(\hat{h}_{\vee}\right)\right|<\varepsilon / 2$ (note that $\left.\hat{h}_{\vee} \in\left(L^{\infty}, l^{1}\right)\right)$. Then

$$
\begin{aligned}
|(\hat{f}-\hat{g})(h)| \leqq & f\left(\hat{h}_{\vee}\right)-f_{s}\left(\hat{h}_{\vee}\right)|+| f_{s}\left(\hat{h}_{\vee}\right)-g_{s}\left(\hat{h}_{\vee}\right) \mid \\
& +\left|g_{s}\left(\hat{h}_{\vee}\right)-g\left(\hat{h}_{\vee}\right)\right| \\
<\varepsilon & +\left|\left(\hat{f}_{s}-\hat{g}_{s}\right)(h)\right| .
\end{aligned}
$$

But $\hat{f}_{s}-\hat{g}_{s}$ vanishes on $\Omega_{n}$ and thus $|(\hat{f}-\hat{g})(h)|<\varepsilon$. Since $\varepsilon>0$ and $h \in A_{c}(\Gamma)$ with supp $(h) \subset \Omega_{n}$ were chosen arbitrarily we deduce that $\hat{f}-\hat{g}$ vanishes on $\Omega_{n}$, so that $f \in T_{m}\left(\Omega_{n}\right)$. Hence $T_{m}\left(\Omega_{n}\right)$ is closed.

Now $\left(L^{\infty}, l^{q}\right)$ is a complete metric space and thus we can apply Baire's category theorem which gives us the existence of positive integers $m_{0}, n_{0}$ such that $T_{m_{0}}\left(\Omega_{n_{0}}\right)$ has nonvoid interior. This means we can find $\delta>0$ and $f_{0} \in T_{m_{0}}\left(\Omega_{m_{0}}\right)$ such that

$$
V=\left\{f \in\left(L^{\infty}, l^{q}\right):\left\|f-f_{0}\right\|_{\infty, q}<\delta\right\} \subset T_{m_{0}}\left(\Omega_{n_{0}}\right) .
$$

Let $k \in\left(L^{\infty}, l^{q}\right)$ and choose nonzero $\alpha$ such that $\|\alpha k\|_{\infty, q}<\delta$. Then $f_{0}, \alpha k+f_{0}$ belong to $V$ and so there exist $g_{0}, g_{1} \in L^{p}(G)$ with $\hat{f}_{0}-\hat{g}_{0}$ and $\left(\alpha k+f_{0}\right)^{\wedge}-\hat{g}_{1}$ vanishing on $\Omega_{n_{0}}$. The linearity of the Fourier transform entails that

$$
\hat{k}-\alpha^{-1}\left(g_{1}-g_{0}\right)^{\wedge}=\alpha^{-1}\left(\left(\alpha k+f_{0}-g_{1}\right)^{\wedge}-\left(f_{0}-g_{0}\right)^{\wedge}\right)
$$

vanishes on $\Omega_{n_{0}}$. But $\alpha^{-1}\left(g_{1}-g_{0}\right) \in L^{p}(G)$; since $k \in\left(L^{\infty}, l^{q}\right)$ was chosen arbitrarily we have a contradiction of Theorem 1 .

Hence our initial assumption was false and, for $p_{0} \in(p, q)$ with $p, q$ as in the statement of the theorem, we have the existence of $f \in\left(L^{\infty}, l^{q}\right)$ such that, for any nonvoid open set $\Omega \subset \Gamma$, there is no $g \in L^{p_{0}}(G)$ for which $\hat{f}-\hat{g}$ vanishes on $\Omega$. Then the same is true with $L^{p_{0}}(G)$ replaced by $\left(L^{1}, l^{p}\right)$. For suppose to the contrary that $\Omega \subset \Gamma$ and $g \in\left(L^{1}, l^{p}\right)$ exist such that $\hat{f}-\hat{g}$ vanishes on $\Omega$; without loss of generality we may assume that $\Omega$ is relatively compact. Then, choosing $k \in\left(L^{p_{0}}, l^{1}\right)$ with $\hat{k}=1$ on $\Omega$, we have that

$$
\hat{f}-(k * g)^{\wedge}=(\hat{f}-\hat{g})+\left(\hat{g}-(k * g)^{\wedge}\right)
$$

vanishes on $\Omega$ and $k * g \in L^{p_{0}}(G)$, contradicting our choice of $f$. This completes the proof of the theorem.

The author would like to thank the referee for some helpful suggestions on an earlier version of this paper. 


\section{REFERENCES}

1. J.-P. Bertrandias, C. Datry et C. Dupuis, Unions et intersections d'espaces $L^{p}$ invariantes par translation ou convolution, Ann. Inst. Fourier (Grenoble), 28 (1978), $53-84$.

2. J.-P. Bertrandias et C. Dupuis, Transformation de Fourier sur les espaces $l^{p}\left(L^{p \prime}\right)$, Ann. Inst. Fourier (Grenoble), 29 (1979), 189-206.

3. Michael Cowling, Some applications of Grothendieck's theory of topological tensor products in harmonic analysis, Math. Ann., 232 (1978), 273-285.

4. John J. F. Fournier, Local complements to the Hausdorff-Young theorem, Michigan Math. J., 20 (1973), 263-276.

5. G. I. Gaudry, Multipliers of type ( $p, q)$, Pacific J. Math., 18 (1966), 477-488.

6. Edwin Hewitt and Kenneth A. Ross, Abstract Harmonic Analysis, Vols. I, II, Die Grundlehren der mathematischen Wissenschaften, Bände 115, 152, Springer-Verlag, Berlin, Heidelberg, New York, 1963, 1970.

7. Lars Hörmander, Estimates for translation invariant operators in $L^{p}$ spaces, Acta Math., 104 (1960), 93-140.

8. Yitzhak Katznelson, An Introduction to Harmonic Analysis, John Wiley and Sons, New York, London, Sydney, Toronto, 1968.

9. James Stewart, Fourier transforms of unbounded measures, Canad. J. Math., 31 (1979), 1281-1292.

Received December 5, 1979 and in revised form December 31, 1980.

MURDOCH UNIVERSITY

PERTH

Western Australia, 6150, Australia 


\title{
PACIFIC JOURNAL OF MATHEMATICS
}

\section{EDITORS}

\author{
DONALD BABBITT (Managing Editor) \\ University of California \\ Los Angeles, CA 90024 \\ Hugo RossI \\ University of Utah \\ Salt Lake City, UT 84112 \\ C. C. MOORE and Arthur Agus \\ University of California \\ Berkeley, CA 94720
}

\section{J. DugundjI}

Department of Mathematics

University of Southern California

Los Angeles, CA 90007

R. FinN and J. Milgram

Stanford University

Stanford, CA 94305

\section{ASSOCIATE EDITORS}
R. ARENS
E. F. BeCKENBACH
B. H. NeumanN
F. WOLF
K. YoshidA

\section{SUPPORTING INSTITUTIONS}

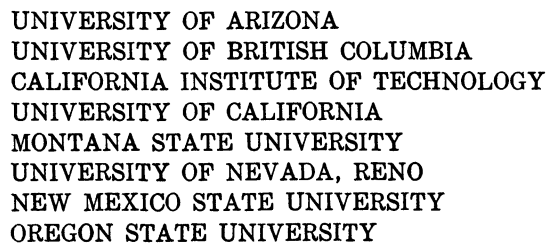

UNIVERSITY OF ARIZONA

UNIVERSITY OF BRITISH COLUMBIA

CALIFORNIA INSTITUTE OF TECHNOLOGY

UNIVERSITY OF CALIFORNIA

MONTANA STATE UNIVERSITY

UNIVERSITY OF NEVADA, RENO

NEW MEXICO STATE UNIVERSITY

OREGON STATE UNIVERSITY

\author{
UNIVERSITY OF OREGON \\ UNIVERSITY OF SOUTHERN CALIFORNIA \\ STANFORD UNIVERSITY \\ UNIVERSITY OF HAWAII \\ UNIVERSITY OF TOKYO \\ UNIVERSITY OF UTAH \\ WASHINGTON STATE UNIVERSITY \\ UNIVERSITY OF WASHINGTON
}

The Supporting Institutions listed above contribute to the cost of publication of this Journal, but they are not owners or publishers and have no responsibility for its content or policies.

Mathematical papers intended for publication in the Pacific Journal of Mathematics should be in typed form or offset-reproduced, (not dittoed), double spaced with large margins. Please do not use built up fractions in the text of the manuscript. However, you may use them in the displayed equations. Underline Greek letters in red, German in green, and script in blue. The first paragraph or two must be capable of being used separately as a synopsis of the entire paper. Please propose a heading for the odd numbered pages of less than 35 characters. Manuscripts, in triplicate, may be sent to any one of the editors. Please classify according to the scheme of Math. Reviews, Index to Vol. 39. Supply name and address of author to whom proofs should be sent. All other communications should be addressed to the managing editor, or Elaine Barth, University of California, Los Angeles, California, 90024.

50 reprints to each author are provided free for each article, only if page charges have been substantially paid. Additional copies may be obtained at cost in multiples of 50 .

The Pacific Journal of Mathematics is issued monthly as of January 1966. Regular subscription rate: $\$ 102.00$ a year (6 Vols., 12 issues). Special rate: $\$ 51.00$ a year to individual members of supporting institutions.

Subscriptions, orders for numbers issued in the last three calendar years, and changes of address shoud be sent to Pacific Journal of Mathematics, P.O. Box 969, Carmel Valley, CA 93924, U.S.A. Old back numbers obtainable from Kraus Periodicals Co., Route 100, Millwood, NY 10546.

\section{PUBLISHED BY PACIFIC JOURNAL OF MATHEMATICS, A NON-PROFIT CORPORATION}

Printed at Kokusai Bunken Insatsusha (International Academic Printing Co., Ltd.). 8-8, 3-chome, Takadanobaba, Shinjuku-ku, Tokyo 160, Japan. 


\section{Pacific Journal of Mathematics}

Vol. 99, No. $2 \quad$ June, 1982

Thomas E. Armstrong and Karel Libor Prikry, On the semimetric on a

Boolean algebra induced by a finitely additive probability measure . . . .249

Walter Russell Bloom, Strict local inclusion results between spaces of

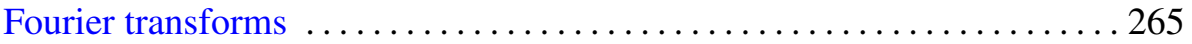

Richard Clark Brown, Notes on generalized boundary value problems in

Banach spaces. II. Infinite-dimensional extension theory ........... 271

Sui Sun Cheng, Isoperimetric eigenvalue problem of even order differential

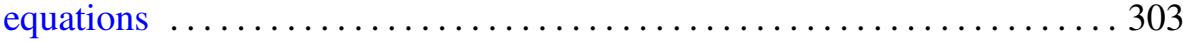

Lung O. Chung and Jiang Luh, Derivations of higher order and

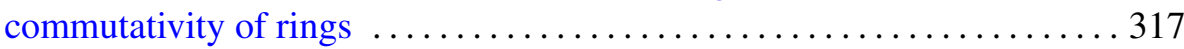

Ali Ahmad Fora, A fixed point theorem for product spaces . . . . . . . . . 327

Barry J. Gardner, Radical classes of regular rings with Artinian primitive

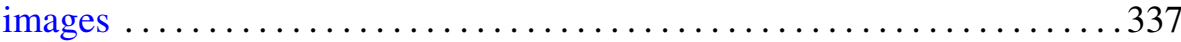

John Brady Garnett and Peter Wilcox Jones, BMO from dyadic BMO . . . 351

Allen E. Hatcher, On the boundary curves of incompressible surfaces . . . . 373

Richard Howard Hudson and Kenneth S. Williams, Resolution of

ambiguities in the evaluation of cubic and quartic Jacobsthal sums .....379

Viktor Losert, Counter-examples to some conjectures about doubly

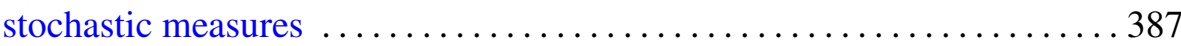

Kenneth Derwood Magill, Jr., P. R. Misra and Udai Bhan Tewari,

Structure spaces for sandwich semigroups

Mark Mandelker, Continuity of monotone functions

Kenneth Guy Miller, An index theorem and hypoellipticity on nilpotent Lie groups ......................................... 419

Evelyn M. Nelson, Homomorphisms of mono-unary algebras . . . . . . . . . 427

Marvin E. Ortel, The support of an extremal dilatation . . .

R. S. Pathak and O. P. Singh, Finite Hankel transforms of distributions . . . 439

Richard Cole Penney, The theory of ad-associative Lie algebras

Linda Ruth Sons, Zero distribution of functions with slow or moderate

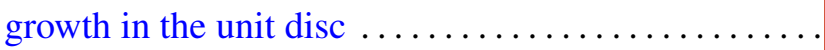

Russell Bruce Walker, Transversals to laminations 